\title{
WestVirginiaUniversity
}

THE RESEARCH REPOSITORY @ WVU

Graduate Theses, Dissertations, and Problem Reports

2007

\section{Assessing public opinion toward homelessness in the United States}

Joni Mari Dugan

West Virginia University

Follow this and additional works at: https://researchrepository.wvu.edu/etd

\section{Recommended Citation}

Dugan, Joni Mari, "Assessing public opinion toward homelessness in the United States" (2007). Graduate Theses, Dissertations, and Problem Reports. 826.

https://researchrepository.wvu.edu/etd/826

This Thesis is protected by copyright and/or related rights. It has been brought to you by the The Research Repository @ WVU with permission from the rights-holder(s). You are free to use this Thesis in any way that is permitted by the copyright and related rights legislation that applies to your use. For other uses you must obtain permission from the rights-holder(s) directly, unless additional rights are indicated by a Creative Commons license in the record and/ or on the work itself. This Thesis has been accepted for inclusion in WVU Graduate Theses, Dissertations, and Problem Reports collection by an authorized administrator of The Research Repository @ WVU. For more information, please contact researchrepository@mail.wvu.edu. 


\title{
Assessing Public Opinion Toward Homelessness in the United States
}

\author{
Joni Mari Dugan
}

\begin{abstract}
Thesis submitted to the
Eberly College of Arts and Sciences

at West Virginia University

in partial fulfillment of the requirements

for the degree of
\end{abstract}

Master of Arts

in

Sociology

\author{
Approved by \\ James J. Nolan III, Ph.D., Chair \\ Susan Pearce, Ph.D. \\ Mohamed Alkadry, Ph.D.
}

Department of Sociology and Anthropology

\author{
Morgantown, West Virginia \\ 2007
}

Keywords: Social disorganization theory, environmental Overload theory, subculture theory, homelessness, empathy, General Social Survey, rural-urban continuum codes 


\begin{abstract}
Assessing Public Opinion Toward Homelessness in the United States

Joni Mari Dugan
\end{abstract}

This study examines the relationship between a variety of demographic characteristics and an individual's feelings and helping behavior towards the homeless population. This study also distinguishes between the way urban residents feel and act towards the problem of homelessness with the way that rural residents feel and act towards the problem of homelessness.

Respondents were identified as urban or rural by using the nine party county codification scheme of rural-urban continuum codes from the United States Department of Agriculture. This study is a secondary data analysis of the 2002 General Social Survey (GSS), which has a sample size of 3,000 noninstitutionalized English speaking adults. Bivariate logistic regression and multivariate logistic regression were used to analyze the data. 


\section{ACKNOWLEDGEMENTS}

I would like to thank my committee Dr. Nolan, Dr. Pearce, and Dr. Alkadry for all of their help and encouragement. I really appreciate the guidance they have given me throughout this endeavor. I would also like to thank my parents for all of their love and support through the years and helping to make me the person I am today. 


\section{$\underline{\text { Table of Contents }}$}

Abstract.............................................................

Acknowledgements...........................................ii

List of Tables.................................................

Introduction.......................................................1

Statement of Problem......................................4

Review of Literature.....................................6

Theoretical Perspective..................................16

Hypotheses.........................................17

Delimitations........................................18

Methods..........................................................19

Discussion of Variables.....................................23

Data Analysis.........................................26

Findings.....................................................27

Discussion and Conclusions...................................50

Limitations and Further Study ............................56

Bibliography................................................59 


\section{$\underline{\text { List of Tables }}$}

Causal

Diagram.......................................................22

Table

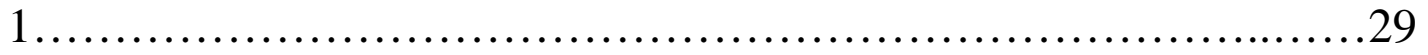

Table

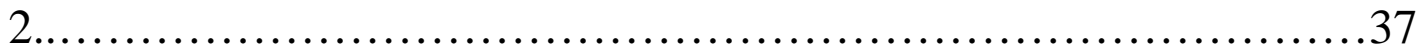

Table

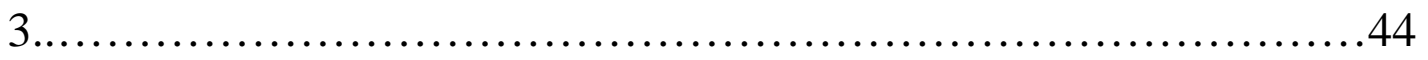




\section{Assessing Public Opinion Toward Homelessness in the United States}

\section{$\underline{\text { Introduction }}$}

The problem of homelessness is not one of which the American people and our leaders are unaware. Homelessness seemed to emerge as a new social problem in the late 1970s and early 1980s (Buck, Toro, and Ramos, 2004). During the 1980s, the number of homeless individuals and families grew all over the country. Most experts agree that modern homelessness began in the United States in the 1980s. In the 1990s, soup kitchens, homeless shelters, and other supportive services became available in cities and towns across the nation. The number of homeless individuals still remained high, even with such services. During the 2000s, research has showed that children and families were the largest growing segment of the homeless population in America. In 1970, there were 300,000 more affordable housing units available than there were low-income households in need. By 2001, dramatic reversal of that trend was in place- there were 4.7 million more low-income households that needed housing than there were affordable housing units. Homelessness is a major social problem in today's society and is therefore worthy of study. Homelessness, however, is a difficult problem to study because the homeless population is a hard population to reach. The media and government leaders present the problem of homelessness to society by using stereotypical frames and tend to influence individual's perceptions of the problem.

The McKinney Act of 1989 is the most important federal legislation to aid homeless persons. The McKinney Act defines homelessness in the following way: 
“1.) An individual who lacks a fixed, regular, and adequate nighttime residence; and 2.) an individual who has a primary nighttime residence that is...A.) A supervised publicly or privately operated shelter designed to provide temporary living accommodations (including welfare hotels, congregate shelters, and transitional housing for the mentally ill); B.)An institution that provides a temporary residence for individuals intended to be institutionalized; or C.) A public or private place not designed for, or ordinarily used as, a regular sleeping accommodation for human beings.” (U.S. Department of Housing and Urban Development, 2001). The largest appropriations of this act were for emergency shelter and assistance while the smallest appropriations went to job training, adult literacy, and alcohol and drug treatment.

Statistics on homelessness are difficult to acquire because of the ambiguous, hidden, and erratic reality of homelessness. The 2005 Annual Progress Report (APR) of the U.S. Department of Housing and Urban Development contains statistics on persons served in all HUD projects in 2005 (includes permanent housing, transitional housing, safe havens, and SSO projects). The total number of all homeless persons served in 2005 was 931, 982 individuals. The percentage of singles served is 53\%, compared with $47 \%$ for persons in families served. The following figures are estimates that represent national averages. Some homeless communities can have increased variability with regards to the geographic location. There are as many as 3.5 million people that experience homelessness in a given year and about 842,000 people in any given week (Substance Abuse and Mental Health Services Administration). According to the National Coalition for the Homeless, $49 \%$ of homeless individuals are African American (compared to $11 \%$ of the general population), 35\% are Caucasian (under-represented compared to $75 \%$ of 
the general population, $13 \%$ are Hispanic (compared to $10 \%$ of the general population), $2 \%$ are Native American (compared to $1 \%$ of the general population), and $1 \%$ are AsianAmerican (under-represented compared to 4\% of the general population) (National Coalition for the Homeless). Fifty-eight percent of homeless individuals report having trouble getting enough food to eat. Education levels of homeless individuals indicate that $38 \%$ have less than a high school diploma, 34\% have a high school diploma or equivalent, and 28\% have more than a high school education (Urban Institute). Seventyone percent of homeless individuals reside in central cities, 21\% are in suburbs, and 9\% are found in rural areas (Substance Abuse and Mental Health Services Administration).

It is important to look at how the general population views the problem of homelessness because the non-homeless are easier to access information about and this type of information may provide useful resources to social scientists, policymakers, and politicians. This study may influence policy makers to improve policies on homelessness by taking into consideration the public's opinions and actions towards homelessness. As a result, better policies may be enacted regarding homeless and/or poor people. The results of this study may provide useful information to social scientists and influence social scientists to do further research on the topic. Finally, this study will contribute to the scholarly literature in the following two ways: this is a difficult topic to study and as a result, there is not a great deal of research done on the topic, and the majority of studies actually look at the homeless population, while this study is intended to look at the general population's feelings and helping behavior towards homelessness.

This study is also important for a variety of other reasons. Homelessness does not just affect homeless individuals. All members of society are affected by homelessness. 
Homelessness has a severe impact on the economy. Taxpayers are paying for homeless individuals' visits to the emergency room and most people do not realize that. Everyone needs to be more aware of the situations that are going on in the world today.

Studies dealing with how individuals view the problem of homelessness tend to look at a variety of factors influencing their perceptions. It has been found that younger and female respondents were more likely to attribute homelessness to economic factors, were less likely to attribute it to personal failings of the homeless, had more compassionate attitudes towards the homeless, and considered it a more serious problem. Those who identify as politically liberal are more likely to consider situational rather than individual influences for negative social outcomes, and were more generous and supportive towards distributive programs such as welfare. Lower socio-economic groups tend to have more generous solutions for the problem of homelessness (e.g. Toro and McDonell 1992; Miller and Seligman 1999). Social and economic concerns are central to the issue of homelessness. Economic attitudes include support for economic aid for homeless people and beliefs about the extent to which structural factors contribute to homelessness. Social attitudes include perceptions of and feelings towards homeless people and support for their civil liberties (Phelan, Link, Stueve, and Moore 1995). Economic and social concerns differ in the way that individuals view the problem of homelessness.

\section{Statement of the Problem}

Various studies have examined different demographic characteristics that influence an individual's perceptions of homelessness. The data collected in these studies seem to be consistent with one another, finding that certain demographic 
characteristics tend to be predictive towards people's feelings and helping behavior towards homeless individuals, while other demographic characteristics are not significant predictors of people's attitudes and feelings towards homelessness. The question that remains is whether an urban resident feels and acts differently towards the homeless population than a rural resident does. Individuals who are homeless may be disconnected from a vital social network and it is equally plausible that homelessness disrupts social networks (Toohey, Shinn, and Weitzman 2004).

Despite the rise of homelessness in the past two decades, there are very few studies that look at how the general population views the problem. Research has been done on homelessness and/or poverty, but there are no studies that compare the way urban residents feel and act towards the problem of homelessness with the way that rural residents feel and act towards the problem of homelessness. It is important to discover if there are any significant differences between rural and urban resident's feelings towards homelessness. If differences do exist, it is important to try to find out why these differences are occurring. Many of the existing studies on homelessness study the problem by observing and interviewing homeless people at shelters or other places intended to help homeless individuals (Zlotnick, Robertson, and Tam 2002; Hill 2003; Toohey, Shinn, and Weitzman 2004; Kidd 2004). Interviewing homeless individuals at shelters may lead to the homeless feeling even more marginalized. Also, some of the existing literature on homelessness seems to be somewhat outdated.

The first research question that this study is going to answer is: What are some of the individual and environmental characteristics that are influential on an individual's feelings and helping behavior towards the homeless population? The other research 
question that this study is going to answer is: Are rural residents more sympathetic and caring towards the problem of homelessness than their urban counterparts? This information is going to be obtained and analyzed from the 2002 General Social Survey. The purpose of this study is to discover the relationship between an individual's demographic characteristics and their feelings and actions towards the problem of homelessness, as well as any differences that exist between urban residents and rural resident's feelings and actions towards the problem of homelessness.

\section{Review of the Literature}

Homelessness has been examined in a number of ways, but it is still a difficult topic to study. In the 1980s homelessness began to be seen as a major urban problem (Hewitt 1996). There is a recent crisis that has occurred in which deindustrialization has affected the United States and the labor market and thus has left millions of people without adequate wages (Mathieu 1993). The increase in poverty concentration has coincided with a dramatic increase in joblessness, female-headed households, welfare dependency, out-of-wedlock births, segregation, and crime (Curley 2005). Research on homelessness in the U.S. may be informed by advances in other countries which give attention to the social construction of poverty and homelessness or the interaction between society and the individual (Committee of the Regions, 1999; Huston \& Liddiard, 1991, 1994).

Even though the government has defined homelessness by using the McKinney Act's definition of homelessness, there is not a general consensus on the definition of homelessness. Literally, homelessness means to be without a home (Farrington and Robinson, 1999). In the scholarly literature, Kelling (1991) has a more useful definition 
of homelessness: "Homelessness is much more than rooflessness; it is the lack of a secure and satisfactory home.” This definition includes the "hidden homeless" population or those people who are "doubling up", staying with friends, or moving from place to place for small periods of time. According to government officials and advocates for the homeless, there are a large number of "hidden" families without shelter. Tens of thousands of poor families-no one can say how many- are living doubled up or tripled up with friends or relatives. In New York City alone in 1986, there were at least 35,000 families living doubled up illegally in apartments owned by the New York City Housing Authority (Nix, 1986). The homeless are commonly defined as those living on the street or staying at emergency shelters, they are shunned by society, have meager possessions if at all, and usually there would be almost no one who would want to be notified if they were seriously ill or died (Layton, 2000). Homelessness has been called the "greatest scourge of our age.” Homeless people are sometimes referred to as derogatory terms such as hobos, tramps, vagrants, beggars, skid-rowers, and down and outs (Kearns, 1984). The homeless may not only suffer severe resource deficits materially and socially, but they are more impoverished in both realms than most other marginalized individuals and groups (Shinn and Gillespie, 1994). Many homeless people live in public spaces and thus homelessness is more disruptive and more visible than other forms of poverty; because of the difficulties involved in cleaning and grooming themselves, many homeless people also may be aesthetically unappealing (Phelan, Link, Moore, and Stueve 1997). Street homelessness can also be referred to as "rough sleeping”. Rough sleeping means exposure to constant stress, physical danger, appalling risks to health, malnutrition, and in all probability a very premature death. The homeless 
population focuses daily survival on getting food, clothing, and some form of shelter. Cultural constructions of homeless people as deviant are at the root of understanding society's response to the problem: "Common use of the term 'the homeless' instead of 'homeless persons' or 'people without homes' facilitates a distancing process. 'They’ become an amorphous, remote, alien mass, lacking individuality or even humanity (Daly, 1996, p.8.).” Homeless people must face stigma along with the many other hardships associated with homelessness.

Homeless individuals often feel a sense of loneliness. According to Rokach (2003), the causes of loneliness were composed of the following five factors: Personal Inadequacy, Developmental Deficits, Unfulfilling Intimate Relationships, Relocation/Significant Separations, and Social Marginality. Current information suggests that homelessness is the result of both structural problems, such as scarce affordable housing and low-paying jobs, and individual characteristics, such as lack of education and substance abuse (Zlotnick, Robertson, and Tam, 2002). Some studies have looked at ways that communities should respond to the problem of homelessness. For example, a HUD document notes that communities should "respond to the particular housing and service needs of different sub-populations of homeless people, such as homeless veterans or people who are homeless with mental illness, HIV/AIDS, victims of domestic violence, and/or histories of substance abuse” (U.S. Department of Housing and Urban Development 1999). More recently it has been recognized that structural factors (e.g. availability of low-income housing or social programs) play as great a role, if not a greater role in determining pathways from poverty to homelessness (Zlotnick, Robertson, and Lahiff 1999). 
Homelessness is often related to deviance. Homeless individuals are often labeled in terms that imply a reduced ability to function as a family member, friend, or citizen (Osborne, 2002). It is expected that the homeless express feelings suggesting that in some ways they are impaired in their ability to interact fully and completely with society (Hill, 2003). The homeless population has been repeatedly characterized as riddled with a higher incidence of disability (e.g., physical, mental, and substance-related) in comparison to the larger population (Shlay and Rossi, 1992). Homeless people have trouble developing personal identities. Homeless individuals often experience a metamorphosis that results in a redefinition of the self, empowering them to adopt a new set of attitudes and behavior patterns that they had not previously considered (Snow and Anderson, 1987). Homeless individuals oftentimes want to restore themselves psychologically and materially, but they face many obstacles to that success. Obstacles to success include poor treatment by members of the larger society, lack of a support network, and interpersonal difficulties among others. Research suggests homelessness may be more accurately portrayed as the result of the convergence of many factors including housing market dynamics, housing and welfare policies, economic restructuring and the labor market, and personal disabilities.

The media has an influence on public opinion concerning the problem of homelessness. News stories suggested that Americans had once been sympathetic to the plight of homeless people but that, after years of over-attention they were now tired of reading and hearing about the issue (Buck, Toro, and Ramos 2004). In the past, people gained most of their knowledge about the homeless from the media (i.e. documentaries, television programs, and movies), but now the homeless can be readily observed on the 
streets. The media continues to depict the "typical homeless person" as male, insane, and drug addicted (Hill, 2003). Films such as Down and Out in Beverly Hills or The Fisher King, and television series like Seinfeld offer unflattering images of the homeless (Forte, 2002). The media may have a strong impact on public opinion. This may be most significant in how it affects the way powerful policy-makers perceive public opinion. Public opinion data may be a tool for developing new policy, as it can help convince policy-makers that changes need to be made. A false perception of collective opinion derived from biased media coverage could prove particularly detrimental when it is held by those with the power to shape public policy (Tompsett et al., 2003). People who hold ambivalent attitudes towards a certain issue or group may be particularly susceptible to persuasive media messages, as they may place greater weight on outside information in their need for resolution of their conflicting attitudes (Maio, Bell, and Esses, 1996). Different approaches used by the media to present an issue can render the message more or less influential.

Some studies have looked at how different demographic characteristics impact the way individuals view and perceive the problem of homelessness. For instance, political party affiliation (Democrats, Republicans, or Independent) influenced judgments about the seriousness of homelessness and support for aid to the homeless (Toro and McDonnell, 1992). Toro and McDonell (1992) found that younger, female, and minority respondents were more likely to attribute homelessness to economic factors, were less likely to attribute it to personal failings of the homeless, had more compassionate attitudes towards the homeless, and considered it a more serious problem. In a study by Federico (2004), it was found that older respondents were less hostile to welfare 
recipients and wealthier respondents were more hostile to welfare. People express greater support for the principle of helping disadvantaged groups than for actual policies aimed at enacting those principles. Previous studies suggest that people respond distinctly and more favorably to assistance for the poor or needy than to "welfare". This is a result of people responding more favorably to the idea if certain terminology is used.

Empathy is a distinct socio-emotional experience that involves "the effort to understand the internal mental and emotional events of other human beings” (Rosenberg, 1990:8). Some researchers state that empathic emotions result from mentally placing oneself in another's position and feeling what another individual might feel in that situation. Education and income are oftentimes related to empathy. Both education and income can enhance opportunities and resources that help people relate to the self and others, and to manage various forms of emotionality.

There is a variety of studies that show a strong and consistent relationship between gender and empathy. Women have self-reported higher levels of empathy than men have. This gender gap may be attributed to differences in socialization processes when people are young. It has been found that empathy tends to be higher among rural residents than among urban residents. Rural people may in fact be more giving to and caring about homeless individuals, but do not define them as homeless because they think of homelessness as an urban problem.

Volunteering is any activity in which time is given freely to benefit another person, group, or cause (Wilson 2000). Volunteers are more likely to rate working to improve their communities, aiding the less fortunate, and doing something for their country higher than non-volunteers (Flanagan et al. 1999). Education increases 
volunteering because it increases empathy, heightens awareness of the problem, and helps to build self-confidence. People of higher socioeconomic statuses tend to volunteer more because they are likely to join more organizations and be more active in them. Individuals that are middle aged tend to rise to their peak of volunteerism. Females in this country are slightly more likely to volunteer than males are. It has been found that whites are more likely to volunteer than individuals from minority groups are and this can be associated with higher levels of socioeconomic status.

Miller and Seligman (1999) examined the effects of political conservatism on attitudes towards distributive justice as a whole, finding that those who identified as politically liberal were more likely to consider situational rather than individual influences for negative social outcomes, and were more generous and supportive towards distributive programs such as welfare. Lower socio-economic groups tend to have more generous ideals towards the problem of homelessness. Expressed religiosity was also strongly associated with intentions to help the homeless (Morgan, Goddard and Givens, 1997). Bunis, Yancik, and Snow (1996) have demonstrated that sympathy for the homeless increases during the holidays, especially around Thanksgiving and Christmas. In a study by Furham, the variables that show the most discriminatory power with regard to beliefs about poverty are income and social class, age, rural/urban background, education, ideological beliefs, religion, and, to a lesser extent, sex (Furnham 1996). The traditional and dominant view is that education fundamentally alters people, changing their characters and basic values in the direction of tolerance of diversity and adherence to democratic values (Adorno, Frenkel-Brunswick, Levinson, and Sanford 1950). The link between education and social liberalism has been called "one of the most stable and 
consistent findings in empirical social research of contemporary American society”.

Left-wing people (and post-materialists), it is said, are more inclined to attribute poverty to social causes, whereas the right-wings are more likely to blame the victims (Furnham 1996).

There has been some research done on the differences between rural homeless individuals and urban homeless individuals. The studies tend to either solely look at urban homelessness or solely look at rural homelessness. Homelessness in rural America is a problem hardly recognized, little understood, and only minimally studied by rural sociologists. Since homelessness in rural America is hard to define, to count, and even to see, it oftentimes goes unnoticed and unaddressed. Homelessness in rural areas seems to be growing. Rural homelessness is a growing concern in American society, and rural homelessness is linked to rural poverty. In America, the best single predictor of ending up homeless is growing up in poverty, whether your background is urban or rural. The rate of poverty in rural areas is increasing more rapidly than in urban areas, with unemployment rates reaching twenty percent.

Homeless individuals in rural areas tend to be less visible than homeless individuals in urban areas because there are fewer social services and shelter programs to assist them (First, Rife, and Toomey, 1994). According to the U.S. Department of Agriculture, many rural citizens feel that homelessness is an urban problem, or that when homelessness exists in rural areas, it affects mainly transients (Pleace 2000). Rural homelessness has always taken a back seat to the more glaring problems in cities. In recent studies, it has been found that there is a lower percentage of rural homeless individuals that report being hospitalized at least once for emotional or mental health 
problems, than urban homeless individuals. A study conducted by Janet Fitchen found that rural homelessness was not highly associated with mental health problems. Factors most frequently contributing to rural homelessness included family conflict, inability to pay rent, and unemployment (Fitchen 1992). A study looking at rural homeless individuals in Ohio found that the faces of homelessness are changing, and there are increasing numbers of rural people, children and families, and people from minority groups becoming homeless (First, Rife, and Toomey, 1994). A second finding by First, Rife, and Toomey is that homeless people in rural areas are younger, more highly educated, more likely to be single women or have children, and are less likely to be disabled. A study done by Flynt found that "Rural poverty rates as a percentage of rural populations are higher than urban poverty rates as a percentage of urban populations” (Flynt, 1996, p.33).

\section{Similar Studies}

There are two studies that are very similar to this proposed plan of study. Toro and McDonnell published an article in 1992 that was a survey of the general public on their opinions, attitudes, and knowledge about homelessness. Tompsett et al. conducted a cross-national analysis looking at a sample of U.S. residents and a sample of residents in Germany and their perceptions on the problem of homelessness. Both of these studies have consistent findings. They found that race, age, income, educational background, political party affiliation, and sex have an impact on the way an individual feels about the problem of homelessness. The hypotheses that have been developed for this study are related to some of the findings from the study done by Toro and McDonnell. The Tompsett et al. study was a cross-national analysis that produced very interesting results. 
This study would be similar in the sense that it is going to compare urban residents' feelings and actions towards homelessness with rural resident's feelings and actions towards homelessness.

Homelessness has been studied since it seemed to emerge as a new social problem in the United States. There is definitely a need for more research to be done to try and understand different aspects of the problem as well as non-homeless individuals feelings towards homelessness. There seem to have been more studies done on homelessness during the late 1980s and early 1990s, because that is when the problem of homelessness seemed to emerge. The majority of the research studying homelessness actually looks at the homeless population. This type of research is useful, but there is a need to understand the problem from the perspective of those not necessarily included in the homeless population. It is important to understand how the general public feels towards the problem and hopefully influence policy makers and politicians to change policies that exist regarding the homeless population. Rural residents need to be equally as engaged as urban residents in the process of framing both research and policy agendas. The studies that have looked at the general population and their opinions seem to have consistent findings. The research done by both Toro and McDonnell, and Tompsett et al. is the most similar to this study. Both of these studies were interested in the attitudes and opinions regarding homelessness. Each of these studies is unique in their own way and this study is going to be unique and look at some different aspects of the problem. Also, it has been found that social class, age, education, and religion etc. influence the attitudes that people have about homelessness. This study would be valuable because some of the research on homelessness seems to be outdated and homelessness has not been studied by 
looking at the problem on an urban vs. rural continuum concerning the general population's feelings and actions towards the problem of homelessness.

\section{Theoretical Perspective}

There are three theoretical perspectives that can help to make predictions about feelings and actions towards homelessness in rural and urban areas: subculture theory, social disorganization theory, and environmental overload theory. Each of these perspectives can contribute to understanding the negative association between urbanism and helping strangers.

Subculture theory is based on the work of Claude Fischer. This theory states that the heterogeneity of large cities produces the absence of communitywide integration and consensus on norms (Amato 1993). The high crime rates and diverse urban population lead to friction between strangers and a lack of trust (Amato 1993). Therefore, individuals in rural areas will be more likely to help strangers in need than their urban counterparts will be.

The social disorganization theory is one of the most important theories developed by the Chicago school. Social disorganization theory suggests that people in large cities, compared with people in small towns, experience deficits in the quality of interpersonal relations (Alexander 1973). Louis Wirth proposed that migration to cities from rural areas disrupts kinship and friendship ties. When people relocate to the city, they find it difficult to establish friendships. There are a few reasons that this difficulty arises: the heterogeneity of urban populations, the continuing residential mobility, and because interactions seem to occur in transitory, superficial roles (Amato 1993). These reasons lead to a weak social integration whose consequences include loneliness, 
depersonalization, tension, and predatory forms of behavior. This theory in turn predicts that feelings and helping actions towards homeless individuals are going to be lower in large cities than in small towns.

Milgram has argued, based on Simmel's work, that urbanites often fail to extend help to strangers because of environmental overload. Environmental overload is a condition resulting from the excessive level of social stimulation in large cities. Milgram stated that people deal with overload by adopting strategies like disregarding low-priority inputs (avoiding strangers), relying on specialized agencies to absorb excess inputs, and screening out stimuli (Amato 1993). Therefore, overload theory predicts that living in a large city will be associated with less helping towards strangers than living in a small town. This theory as related to this study will predict that those living in urban areas will have more negative attitudes towards homelessness and be less likely to help homeless individuals than those individuals living in a small town or rural area.

\section{Hypotheses}

Hypothesis 1- There will be a difference between the way urban residents feel and act towards the problem of homelessness with the way that rural residents feel and act towards the problem of homelessness. I expect to find that rural residents will have more sympathetic attitudes towards homelessness and will be more likely to give to the homeless than urban residents will be.

Hypothesis 2- Younger individuals will have more compassionate attitudes toward the homeless and will be more likely to give to the homeless than older individuals will be. Hypothesis 3- Females will have more compassionate attitudes toward the homeless population and will be more likely to give to the homeless than males will be. 
Hypothesis 4- Individuals who are Democrats will be more generous and supportive of distributive programs like welfare and the homeless population than individuals who are members of any other political party.

Hypothesis 5- Individuals from lower income groups will have more generous attitudes and behavior towards homelessness than individuals from higher income groups.

Hypothesis 6- Race will have an impact on the way an individual feels and acts towards homelessness, with minorities being more sympathetic and giving than whites will be. Hypothesis 7- Individuals who have higher levels of education will have attitudes that are more generous and be more likely to give to the homeless than individuals who have lower levels of education.

Hypothesis 8- Individuals from the South will have attitudes that are more generous and be more likely to give to the homeless than individuals from any other region of the United States.

Hypothesis 9- Individuals who are more empathic will have attitudes that are more generous and be more likely to give to the homeless than less empathic individuals are.

\section{Delimitations}

The purpose of this study is to gain a general understanding of how urban residents feel and act toward the problem of homelessness and compare that with the way rural residents feel and act toward the problem of homelessness. This study is also aimed at understanding how a variety of demographic characteristics influence an individual's feelings and actions toward homelessness. It would be entirely too difficult to try and collect my own data for this study and that is why I have decided to use secondary data analysis of the 2002 General Social Survey. 
There is going to be a specified set of variables (demographic characteristics and rural-urban continuum codes) used to determine the impact they have on the respondent's feelings and actions towards the problem of homelessness. This is feasible because it is looking only at a number of characteristics, rather than all possible characteristics that could be influential on a respondent's feelings and actions towards homelessness. It would be very difficult to try and look at all characteristics that could possibly influence the respondent's perceptions.

This study is using a national area probability sample of non-institutionalized adults (the 2002 GSS' sample). This is narrowing the scope of the study by looking at a sample of the population of non-institutionalized adults rather than the entire population of non-institutionalized adults.

\section{$\underline{\text { Methods }}$}

\section{Data}

The General Social Survey (GSS) began in 1972 and includes a standard core of demographic and attitudinal questions, as well as questions on topics of special interest. The 2002 General Social Survey is cross-sectional data collected at only one point in time. The instrument used for this study is an intact instrument designed for the 2002 General Social Survey. Main areas covered in the GSS include socioeconomic status, social mobility, social control, the family, race relations, sex relations, civil liberties, and morality. During each year of GSS data collection, the National Opinion Research Center (NORC) incorporates methodological experiments. These include question wording, context effects, use of different types of response scales, and assessments of validity and reliability. The GSS is the largest project funded by the Sociology Program 
of the National Science Foundation. The GSS is the most frequently analyzed source of information in the social sciences, besides the U.S. Census. It is a major teaching tool used for research and dissertations, and it is also used as a method of teaching in many classrooms.

The exact wording of questions remains the same in order to conduct time trend studies, as well as replications of earlier findings. Some questions are asked in only a random sub-sample of the households, other questions are asked in other households, and finally some questions are asked of all the respondents. Even though only a sub-sample of respondents were asked some of the questions, the responses are still representative of the U.S. population, except that there will be a higher degree of sampling error. Participants take part in an in-person interview that takes place for about ninety minutes. The General Social Survey became biennial in 1994, and since then has had a sample size of 3,000 people. The 2002 General Social Survey used in this study has a response rate of $70 \%$.

The GSS is a national area multistage probability sample of non-institutionalized, English speaking adults. First, the researchers select a random sample of cities and counties across the country, grouping them in a way that ensures that those selected will reflect all the variations in cities and counties in the nation. The researchers then select a random sample of city blocks or equivalent units in rural areas within each of the selected cities or counties.

The 2003 Rural-Urban Continuum Codes are used to define the respondents as urban or rural. These codes are designed by the standard Office of Management and Budget (OMB) of the United States Department of Agriculture. This coding scheme was 
originated in 1975 by David L. Brown, Fred K. Hines, and John M. Zimmer. The 2003 Rural-Urban Continuum Codes form a classification scheme that distinguishes metropolitan (metro) counties by the population size of their metro area, and nonmetropolitan (non-metro) counties by degree of urbanization and adjacency to a metro area or areas. The metro and non-metro categories are subdivided into three metro and six non-metro groupings that make up a nine part county codification, with one being the most urban and nine being the most rural. The 2003 Urban-Rural Continuum Codes consist of 1,089 metro counties and 2,052 non-metro counties, with independent cities of Virginia being combined with their counties of origin.

The following diagram is a causal diagram designed to visually show the hypotheses that were created. This diagram shows the predicted relationship between the independent variables and the dependent variables. The red lines indicate that the group in that circle is more likely to have given food or money to a homeless person, more likely to think that we are spending the right amount or too much on solving the problems of big cities, and more likely to agree with the statement, "Personally assisting people in trouble is very important to me”. The blue lines indicate that the group in that circle is less likely to have given food or money to a homeless person, less likely to think that we are spending the right amount or too much on solving the problems of big cities, and less likely to agree with the statement, "Personally assisting people in trouble is very important to me”. 


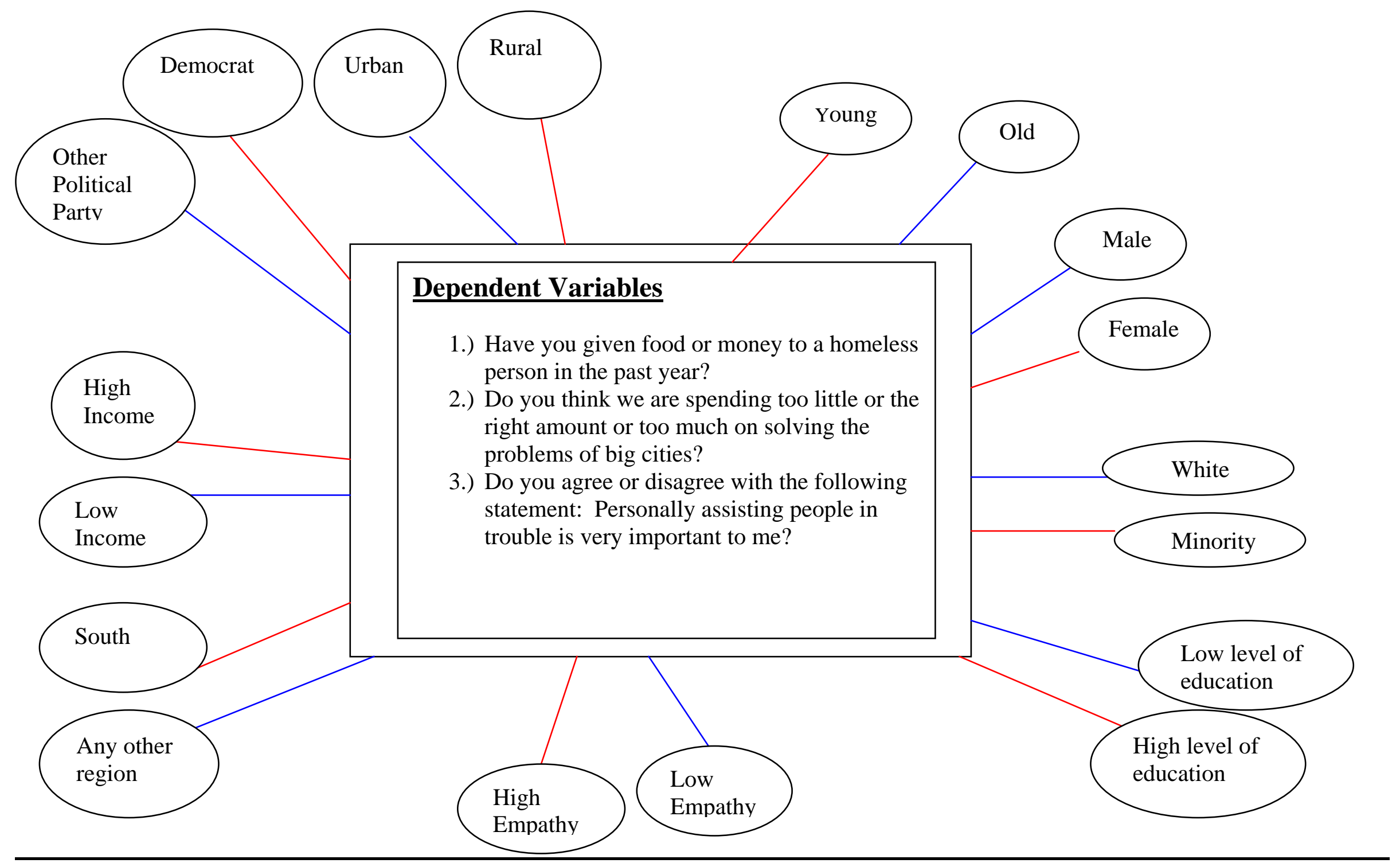




\section{Discussion of Variables}

\section{Independent Variables}

Income

Income is the total family income from all sources last year before taxes. Income was recoded as follows: under \$1,000 (0), \$1,000-9,999 (1), \$10,000-24,999 (2), $\$ 25,000$ or over (3), or refused (4).

\section{Educational Attainment}

Educational attainment is the total number of years of education the respondent has completed. The values for education were recoded as follows: none (0), less than high school (1), high school graduate (2), some college (3), college graduate (4), or graduate school (5).

\section{Political Party Affiliation}

Political party identification is whether the respondent is a Democrat (0), an Independent (1), a Republican (2), or other (3). Since this is a categorical variable, Democrat (0) is going to be used as the reference category. Race

Race is whether the respondent is white (0) or a minority (1). Since this is a categorical variable, white is going to be used as the reference category. Sex

Sex is defined as whether the participant is a male (1) or a female (2). Since this is a categorical variable, male (1) is going to be used as the reference category. 
Age

Age will be defined as how old (in years) the respondent is at the time of the interview.

\section{Region of Interview}

The region of interview is what region of the United States the interview took place in out of the following recoded categories: South (1), Northeast (2), Central (3), West (4). Since this is a categorical variable, South (1) is going to be used as the reference category.

\section{Rural-urban Continuum Code}

The Rural-urban Continuum Codes distinguish between metropolitan counties by the population size of their metro area, and non-metropolitan counties by degree of urbanization and adjacency to a metro area or areas. Rural-urban Continuum codes have the following values and descriptions: county in metro area of 1 million or more (1), county in metro area of 250,000-1 million population (2), county in metro area of fewer than 250,000 population (3), non-metro county with urban population of 20,000 or more and adjacent to a metro area (4), non-metro county with urban population of 20,000 or more and not adjacent to a metro area (5), non-metro county with urban population 2,500-19,999 and adjacent to a metro area (6), non-metro county with urban population of 2,500-19,999 and not adjacent to a metro area (7), non-metro county completely rural or less than 2,500 urban population and adjacent to a metro area (8), and a non-metro county completely rural or less than 2,500 urban population, and not adjacent to a metro area (9). 


\section{Empathy Scale}

On the 2002 GSS, the seven-item Davis Empathy Scale is used to measure empathy. The Davis Empathy Scale has seven items with values running from seven (for someone giving the least empathic response to all items) to 35(for the most empathic response to all items). Three of the items had to be reverse coded because they were negatively worded. The seven items asked respondents to say how well each item describes them with one indicating it does not describe you very well and five indicating that it does describe you very well. The seven items included in the scale (after being reverse coded) are: “Have tender feeling for people less fortunate”, "Does feel sorry for people having the problem”, "Feels protective towards people taken advantage of”, "Others misfortunes do disturb me", "Does feel pity for someone treated unfairly", “Often quite touched by things”, and "Describes oneself as a soft-hearted person”. The Cronbach's alpha for this scale is .746. This value is above .7, so the scale can be considered reliable with our sample. Secondly, each item in the Corrected Item-Total Correlation column is above .3, which is good and means that the item is not measuring something different from the scale as a whole.

\section{Dependent Variables}

\section{Natcity}

This question states- "We are faced with many problems in this country, none of which can be solved easily or inexpensively. I am going to name some of these problems, and for each one I would like you to tell me whether you think we are spending too much money on it, too little money, or about the right amount. Do you think we are spending too much money on it, too little money, or about the right amount on solving 
the problems of big cities?” I recoded this variable into values of $0-1$ so that logistic regression could be used for the data analysis. Too little is coded as (0) and the right amount or too much is coded as (1).

\section{Givhmlss}

This question asks: "During the past 12 months have you given food or money to a homeless person?” The values are recoded into a 0 -1 format so that logistic regression could be used for data analysis. Not at all in the past year is coded as (0) and at least once in the past year is coded as (1).

\section{Peoptrbl}

This question asks respondents- "Whether they strongly agree, agree, neither agree or disagree, disagree, or strongly disagree to the following statement: Personally assisting people in trouble is very important to me.” The values were recoded into a 0-1 format so that logistic regression could be used for data analysis. Do not agree is coded as (0) and agree is coded as (1).

\section{Data Analysis}

Using the Statistical Package for the Social Sciences (SPSS), bivariate logistic regression and multivariate logistic regression tests were used in order to analyze the data. Each of the three dependent variables is going to be tested and the results are going to be displayed in a table. Each table will list the beta coefficient, standard error, significance, the odds ratio, and the Cox and Snell R square. There are going to be four models included in each of the three tables. The first model for each dependent variable is going to include the following independent variables: age, sex, and race. The second model for each dependent variable is going to include the following independent 
variables: age, sex, race, education, income, and political party identification. The third model for each dependent variable is going to include the following independent variables: age, sex, race, education, income, political party identification, region, and the Rural-urban continuum code. The fourth model for each dependent variable is going to include the following independent variables: age, sex, race, education, income, political party identification, region, the Rural-urban continuum code, and empathy total.

This format was selected so that it will be clear to see how adding certain independent variables to the model will affect the results of this study. It is going to be interesting to see how the results change from one model to the next. The first model consists of characteristics of the person. The second model consists of characteristics of the person and personality characteristics. The third model consists of characteristics of the person, personality characteristics, and geographic identifiers. The fourth model consists of characteristics of the person, personality characteristics, geographic identifiers, and level of empathy.

\section{Findings}

The results of the bivariate logistic regression are discussed for each of the three dependent variables. The results of the multivariate logistic regression are displayed in each of the three tables and the results are discussed following each table. Table 1 shows the results for the Givhmlss dependent variable. Table 2 shows the results for the Natcity dependent variable. Table 3 shows the results for the Peoptrbl dependent variable.

First, bivariate logistic regression was used to test each of the independent variables alone with the dependent variable Givhmlss. The following independent variables were found to be significant when bivariate logistic regression was used: sex, 
race, party id (Democrat-Independent), party id (Democrat-Republican), region (SouthWest), rural-urban continuum code, and the empathy total. Age, education, income, party id (Democrat-other), region (South-Northeast), and region (South-Central) were found to be not significant when bivariate logistic regression was used. Now, I would like to look at how adding certain independent variables to each of the different models will affect the significance level and overall impact on the model. 
Table 1: Multivariate Logistic Regression for Givhmlss

\begin{tabular}{|c|c|c|c|c|c|c|c|c|c|c|c|c|}
\hline & \multicolumn{3}{|c|}{ Model 1} & \multicolumn{3}{|c|}{ Model 2} & \multicolumn{3}{|c|}{ Model 3} & \multicolumn{3}{|c|}{ Model 4} \\
\hline & $\mathbf{B}$ & S.E & $\begin{array}{l}\text { Odds } \\
\text { Ratio }\end{array}$ & B & S.E. & \begin{tabular}{|l} 
Odds \\
Ratio
\end{tabular} & B & S.E. & $\begin{array}{l}\text { Odds } \\
\text { Ratio }\end{array}$ & $\mathbf{B}$ & S.E. & $\begin{array}{l}\text { Odds } \\
\text { Ratio }\end{array}$ \\
\hline Age & -.003 & .003 & .997 & -.002 & .003 & .998 & -.001 & .004 & .999 & -.003 & .004 & .997 \\
\hline Sex (Female) & $.236^{*}$ & .114 & 1.266 & $.238^{*}$ & .118 & 1.269 & $.234^{*}$ & .119 & 1.264 & -.003 & .127 & .997 \\
\hline Race (Minority) & $.585 *$ & .154 & 1.795 & $.545^{*}$ & .166 & 1.725 & $.484^{*}$ & .169 & 1.622 & $.557 *$ & .176 & 1.745 \\
\hline Education & & & & $.123^{*}$ & .051 & 1.131 & .094 & .052 & 1.099 & .071 & .053 & 1.074 \\
\hline Income & & & & .055 & .082 & 1.057 & .029 & .083 & 1.029 & .021 & .086 & 1.022 \\
\hline Party ID (Independent) & & & & -.183 & .144 & .833 & -.146 & .146 & .864 & -.165 & .148 & .848 \\
\hline Party ID (Republican) & & & & -.277 & .157 & .758 & -.271 & .160 & .762 & -.224 & .163 & .800 \\
\hline Party ID (other) & & & & -.533 & .477 & .587 & -.562 & .483 & .570 & -.638 & .501 & .528 \\
\hline Region(Northeast) & & & & & & & -.308 & .165 & .735 & -.213 & .170 & .808 \\
\hline Region (Central) & & & & & & & -.059 & .156 & .943 & .055 & .160 & 1.057 \\
\hline Region (West) & & & & & & & .279 & .177 & 1.322 & $.361 *$ & .180 & 1.435 \\
\hline Rural-Urban Continuum Code & & & & & & & $-.116^{*}$ & .035 & .891 & $-.123 *$ & .035 & .885 \\
\hline Empathy Total & & & & & & & & & & $.076^{*}$ & .013 & 1.079 \\
\hline Cox \& Snell R Square & Model & $1=.01$ & & Mode & $2=.0$ & & Model & $3=.03$ & & Model & $4=.06$ & \\
\hline
\end{tabular}

*Significant at the .05 level

For the categorical variables, the reference categories/values are as follows:

Sex- Reference category male (1)

Race-Reference category white (0)

Party ID- Reference category Democrat (0)

Region- Reference category South (1) 
Table 1-Model 1 shows the results for multivariate logistic regression for the independent variables considered to be characteristics of the person, with the dependent variable asking whether the respondent has given food or money to a homeless person in the past year. Both sex and race were found to be significant in Model 1, while age was found to be non-significant. In Table 1-Model 1, age was negatively associated with giving food or money to a homeless person in the past year, while sex and race were both positively associated with giving food or money to a homeless person in the past year. The variable with the strongest relationship was found between race and giving food or money to a homeless person in the past year. The odds-ratio indicates that minorities are 1.795 times more likely to have given food or money to a homeless person in the past year than whites are. This finding supports hypothesis 6 which states that minorities will be more giving to homeless individuals than whites will be. The other significant independent variable for this model was sex. The odds are $26.6 \%$ higher for females than for males having given food or money to a homeless person in the past year. This finding supports hypothesis 3 which says that females are more giving to the homeless population than males are.

Table 1- Model 2 shows the results for multivariate logistic regression for the independent variables considered to be characteristics of the person and personality characteristics with the dependent variable Givhmlss. Sex, race, and education were found to be significant in Model 2. Age, income, political party (Democrat-Independent), political party (Democrat-Republican), and political party (Democrat-other) were found to be non-significant in Model 2. In Table 1-Model 2, age and party affiliation as either Independent, Republican, or other as compared to being a Democrat were all negatively 
associated with giving food or money to a homeless person in the past year. Sex, race, education, and income were all positively associated with giving food or money to a homeless person in the past year. The variable with the strongest relationship was again found between race and giving food or money to a homeless person in the past year. The odds-ratio is slightly lower than in Model 1, indicating that minorities are 1.725 times more likely to have given food or money to a homeless person in the past year than whites are. This finding also supports hypothesis 6 . The odds ratio for sex indicates that females are 1.269 times more likely to have given food or money to a homeless person in the past year than males are. This finding supports hypothesis 3. Finally, for each increase of 1 on the education scale (no schooling-less than high school, less than high school-high school graduate, high school graduate-some college, some college-college graduate, college graduate-graduate school), the odds of a person having given food or money to a homeless person in the past year is $13.1 \%$ higher. This finding supports hypothesis 7, which states that individuals with higher levels of education will be more giving to the homeless than people with lower levels of education.

Table 1-Model 3 shows the results for multivariate logistic regression for the independent variables considered to be characteristics of the person, personality characteristics, and geographic identifiers with the dependent variable Givhmlss. Sex, race, and the rural-urban continuum codes were found to be significant in Model 3. Age, race, education, income, political party (Democrat-Independent), political party (Democrat-Republican), political party (Democrat-other), region (South- Northeast), region (South-Central), region (South-West) were all non-significant variables in Model 3. In Table 1-Model 3 age, being either Independent, Republican, or other as compared 
to being a Democrat, being from the Northeast or Central region as compared to being from the South, and the rural-urban continuum codes were all negatively associated with having given money or food to a homeless person in the past year. Sex, race, education, income, and being from the West as compared to being from the South were all positively associated with having given money or food to a homeless person in the past year.

The variable with the strongest relationship was again found between race and giving food or money to a homeless person in the past year in Table 1-Model 3. The odds-ratio is slightly lower than in Model 2, indicating that minorities are 1.622 times more likely to have given food or money to a homeless person in the past year than whites are. This again supports the hypothesis about race. The odds are $26.4 \%$ higher for females than for males, for having given food or money to a homeless person in the past year. This finding supports the hypothesis about sex. Finally, the odds-ratio for the rural-urban continuum codes is comparing a 1 unit increase on the scale going from 1(most urban)-9(most rural), with having given food or money to a homeless person in the past year. The odds-ratio for the rural-urban continuum codes indicates that for each increase of 1 as you go towards being more rural, the odds of having given food or money to a homeless person are only .891 as large. This would indicate that when comparing a person who is a 1 ( most urban) with a person who is a 9 (most rural), the person who is a 1 will be 7.128 times more likely to have given food or money to a homeless person in the past year than the person who is a 9. This finding does not support our hypothesis that predicts rural people are more likely to give to homeless individuals than urban people are. The opposite was actually supported. Urban people are more likely to have given food or money to a homeless person in the past year than 
rural people are. According to the Substance Abuse and Mental Health Services Administration, $71 \%$ of homeless individuals reside in central cities, $21 \%$ are in suburbs, and $9 \%$ are found in rural areas. These numbers provide support for the idea that people living in urban areas encounter homeless individuals much more frequently than people living in rural areas do and as a result have many more opportunities to give food or money to a homeless person.

Table 1-Model 4 shows the results for multivariate logistic regression for the independent variables considered to be characteristics of the person, personality characteristics, geographic identifiers, and the empathy total with the dependent variable Givhmlss. Race, region (South-West), rural-urban continuum codes, and the empathy total were the variables found to be significant in Model 4. Age, sex, education, income, political party (Democrat-Independent), political party (Democrat-Republican), political party (Democrat-other), region (South-Northeast), and region (South-Central) were found to be non-significant variables in Model 4. Age, sex, being either Independent, Republican, or other as compared to being a Democrat, being from the Northeast as compared to being from the South, and the rural-urban continuum code are all negatively associated with having given food or money to a homeless person in the past year. Race, education, income, being from the Central region or West as compared to being from the South, and the empathy total are all positively associated with having given food or money to a homeless person in the past year.

In Table1-Model 4, the variable with the strongest relationship was again found between race and having given food or money to a homeless person in the past year. The odds-ratio is slightly higher than in Model 3, indicating that minorities are 1.745 times 
more likely to having given food or money to a homeless person in the past year as whites are. This finding provides support for our race hypothesis. The odds-ratio for region (3) is the comparison between people from the West with people from the South. It indicates that people from the West are 1.435 times more likely to have given food or money to a homeless person in the past year as people from the South are. This finding is not consistent with hypothesis \#8 that states people from the South are more giving to the homeless population than people from any other region. The odds-ratio for the ruralurban continuum codes indicates that for each increase of one as you go towards being more rural, the odds of having given food or money to a homeless person in the past year are only .885 times as large. This would indicate that when comparing a person who is a 1 (most urban) with a person who is a 9 (most rural), the person who is a 1 will be 7.08 times more likely to have given food or money to a homeless person in the past year than a person who is a 9. This finding again does not support hypothesis 1 . The odds-ratio for the empathy total indicates that for each 1-unit increase on total level of empathy, individuals are 1.079 times more likely to have given food or money to a homeless person in the past year. Since the scale for empathy ranges from 7-35, this is quite an extreme value. A person with a score of 35 on the empathy scale will be 30.212 times more likely to have given food or money to a homeless person in the past year than a person with a score of seven on the empathy scale. This finding supports hypothesis 9 , which says that people who are more empathic will be more likely to give to the homeless than individuals who are less empathic.

It is interesting to see that neither age nor income was found to be significant in any of the four multivariate logistic regression models or when bivariate logistic 
regression was used. This finding is inconsistent with some previous studies and literature which said that younger people will be more likely to give to the homeless and people from lower income groups will be more likely to give to the homeless. The hypothesis that younger people are more compassionate and giving to the homeless than older people was not supported by the results of Table 1. Also, the hypothesis that people from lower income groups are more compassionate and giving to the homeless than people from higher income groups was not supported according to the results of Table 1.

Race, the rural-urban continuum codes, and the empathy total are the most significant variables in predicting whether an individual has given food or money to a homeless person in the past year. Each of these variables is significant in each of the models in which they were used. Race seems to be the most significant predictor in all of the models for having given food or money to a homeless person in the past year because race had the highest odds-ratio in each of the models. This finding is inconsistent with some previous studies that have found race to be somewhat predictive of giving to the homeless, but not as predictive as what this study has found race to be. This finding may be related to the overrepresentation of white people in this sample. The 2002 General Social Survey had 2, 765 respondents, 2,188 of which are white, and 577 of which are minorities. This is most likely a contributing factor for race being significant in each of the four models in Table 1.

It is very interesting that the opposite is turning out to be true for this study concerning the differences between rural and urban people's responses to having given food or money to a homeless person in the past year. Urban people are more likely to have given food or money to a homeless person in the past year than rural people are. 
This finding may be attributed to a variety of factors. It is extremely likely that homelessness is much more of a problem in urban areas than in rural areas. This would give urban people many more opportunities to give food or money to a homeless person, than rural people would have, because rural people may not ever encounter homeless individuals. Also, it may be possible that rural people hold more self-sufficient attitudes than urban people and thus feel that people should be able to support themselves and not rely on others for any type of help. C. Wright Mills' book, “The Sociological Imagination" has a quote that can make sense of this phenomenon. "When, in a city of $1,000,000$, only one man is unemployed, that is his personal trouble, and for its relief we properly look to the character of the man, his skills, and his immediate opportunities. But when in a nation of 50 million employees, 15 million men are unemployed, that is an issue, and we may not hope to find its solution within the range of opportunities open to any one individual” (C. Wright Mills, 1959, pg. 9). This quote can directly relate to homelessness in urban areas compared to homelessness in rural areas. Another possible explanation for this finding is that people in very rural areas may only encounter one homeless individual, while people in very urban areas may encounter thousands of homeless individuals. Rural individuals may attribute one homeless individual's problem to personal failings. Urban individuals may see many more homeless individuals and attribute this to being a major issue in today's society due to a variety of factors. People in their respective areas may think similarly about homeless individuals as to the above quote by C. Wright Mills on unemployment. Now, let’s look at the results for Table 2. 
Table 2: Multivariate Logistic Regression for Natcity

\begin{tabular}{|c|c|c|c|c|c|c|c|c|c|c|c|c|}
\hline & \multicolumn{3}{|c|}{ Model 1} & \multicolumn{3}{|c|}{ Model 2} & \multicolumn{3}{|c|}{ Model 3} & \multicolumn{3}{|c|}{ Model 4} \\
\hline & $\mathbf{B}$ & S.E & $\begin{array}{l}\text { Odds } \\
\text { Ratio }\end{array}$ & $\mathbf{B}$ & S.E. & $\begin{array}{l}\text { Odds } \\
\text { Ratio }\end{array}$ & $\mathbf{B}$ & S.E. & $\begin{array}{l}\text { Odds } \\
\text { Ratio }\end{array}$ & $\mathbf{B}$ & S.E. & $\begin{array}{l}\text { Odds } \\
\text { Ratio }\end{array}$ \\
\hline Age & .004 & .003 & 1.004 & .004 & .004 & 1.004 & .004 & .004 & 1.004 & .003 & .005 & 1.003 \\
\hline Sex (Female) & $-.318^{*}$ & .117 & .727 & $-.309 *$ & .120 & .734 & $-.313^{*}$ & .121 & .732 & -.205 & .185 & .815 \\
\hline Race (Minority) & $-.616 *$ & .145 & .540 & $-.494 *$ & .157 & .610 & $-.524 *$ & .160 & .592 & $-.860 *$ & .243 & .423 \\
\hline Education & & & & .094 & .052 & 1.099 & $.111^{*}$ & .053 & 1.118 & .102 & .079 & 1.108 \\
\hline Income & & & & -.083 & .083 & .920 & -.072 & .083 & .930 & -.076 & .127 & .927 \\
\hline Party ID (Independent) & & & & .252 & .145 & 1.287 & .243 & .146 & 1.275 & .046 & .215 & 1.047 \\
\hline Party ID (Republican) & & & & $.326 *$ & .158 & 1.386 & .287 & .160 & 1.332 & .228 & .243 & 1.256 \\
\hline Party ID (other) & & & & -.271 & .456 & .763 & -.298 & .457 & .742 & .074 & .905 & 1.077 \\
\hline Region(Northeast) & & & & & & & -.292 & .169 & .747 & -.491 & .257 & .612 \\
\hline Region (Central) & & & & & & & -.305 & .159 & .737 & $-.563 *$ & .233 & .569 \\
\hline Region (West) & & & & & & & $-.400^{*}$ & .170 & .670 & $-.570^{*}$ & .257 & .565 \\
\hline Rural-Urban Continuum Code & & & & & & & .039 & .037 & 1.040 & .060 & .057 & 1.062 \\
\hline Empathy Total & & & & & & & & & & $-.070 *$ & .079 & .932 \\
\hline Cox \& Snell R Square & Model & $1=.023$ & & Model & $=.029$ & & Model & $3=.036$ & & Model & $=.075$ & \\
\hline
\end{tabular}

*Significant at the .05 level

For each of the categorical variables, the reference categories/values are as follows:

Sex- Reference category male (1)

Race- Reference category white (0)

Party ID- Reference category Democrat (0)

Region- Reference category South (1) 
First, bivariate logistic regression was used to test each of the independent variables alone with the dependent variable Natcity. The following independent variables were found to be significant for Natcity when bivariate logistic regression was used: sex, race, education, party id (Democrat-Independent), party id (Democrat- Republican), region (South-Northeast), region (South-West), and the empathy total. Age, income, party id (Democrat-other), region (South-Central), and the rural-urban continuum code were found to be non-significant variables. Now, I would like to look at how adding certain independent variables to each of the models will affect the significance level and the overall impact on the model.

Table 2-Model 1 shows the results for multivariate logistic regression for the independent variables considered to be characteristics of the person with the dependent variable Natcity. Sex and race were both found to be significant, while age was found to be non-significant in Table 2-Model 1. In Table 2-Model 1, sex and race were both negatively associated with Natcity, meaning that females were more likely than males, and minorities were more likely than whites to feel that we are spending too little on solving the problems of big cities. Age was positively associated with Natcity, meaning that for each year that you get older, you are 1.004 times more likely to feel that we are spending the right amount or too much on solving the problems of big cities. The odds are $27.3 \%$ lower for females than for males to say that we are spending the right amount or too much on solving the problems of big cities. The odds are $46 \%$ lower for minorities than for whites in feeling that we are spending the right amount or too much on solving the problems of big cities. 
Table 2-Model 2 shows the results for multivariate logistic regression for the independent variables considered to be characteristics of the person and personality characteristics with the dependent variable Natcity. Sex, race, and party id (DemocratRepublican) were all found to be significant in Table 2-Model 2. Age, education, income, party id (Democrat-Independent), and party id (Democrat-other) were found to be non-significant variables in Model 2. Age, education, and party id (Democrat-other) were all positively associated with the way a respondent feels about how much we are spending on solving the problems of big cities. For example, for each year that you get older you are 1.004 times more likely to feel that we are spending the right amount or too much on solving the problems of big cities. For each increase of 1 on the education scale (no school-less than high school, less than high school-high school graduate, high school graduate-some college, some college-college graduate, college graduate-graduate school), an individual is 1.099 times more likely to feel that we are spending the right amount or too much on solving the problems of big cities. Sex, race, income, and party id (Democrat-other) were all negatively associated with the way a respondent feels about how much we are spending on solving the problems of big cities. The odds of females feeling we are spending the right amount or too much on solving the problems of big cities are only .734 as large as for males. The odds-ratio for race indicates that minorities are .610 as likely to say that we are spending the right amount or too much on solving the problems of big cities as whites are. The odds are $38.6 \%$ higher for Republicans than for Democrats to feel that we are spending the right amount or too much on solving the problems of big cities. 
Table 2-Model 3 shows the results for multivariate logistic regression for the independent variables considered characteristics of the person, personality characteristics, and the geographic identifiers with the dependent variable Natcity. Sex, race, education, and region (South-West) were all found to be significant in Table 2-Model 3. Age, income, political party (Democrat-Independent), political party (Democrat-Republican), political party (Democrat-other), region (South-Northeast), and region (South-Central) were all found to be non-significant variables in Model 3. Age, education, party id (Democrat-Independent), party id (Democrat-Republican), and the rural-urban continuum codes are all positively associated with the way a respondent feels about how much we are spending on solving the problems of big cities. Sex, race, income, party id (Democrat-other), region (South-Northeast), region (South-Central), and region (SouthWest) are all negatively associated with how a respondent feels about how much we are spending on solving the problems of big cities.

The odds are $26.8 \%$ lower for females than for males to feel that we are spending the right amount or too much on solving the problems of big cities in Model 3. The odds are $40.8 \%$ lower for minorities than for whites to feel that we are spending the right amount or too much on solving the problems of big cities in Model 3. The odds-ratio for each increase of 1 on the education scale (no school-less than high school, less than high school-high school graduate, high school graduate-some college, some college-college graduate, college graduate-graduate school), indicates that individuals are 1.118 times more likely to feel that we are spending the right amount or too much on solving the problems of big cities. When comparing individuals from the West with individuals from the South, the odds are 33\% lower for people from the West than from the South, to feel 
that we are spending the right amount or too much on solving the problems of big cities. For each increase of 1 on the rural-urban continuum code scale (going from most urbanmost rural), individuals are 1.040 times more likely to feel that we are spending the right amount or too much on solving the problems of big cities. When comparing an individual who is a 1 (most urban) with an individual who is a 9 (most rural), the individual who is very rural will be 8.32 times more likely to feel that we are spending the right amount or too much on solving the problems of big cities than the individual who is very urban. This finding may occur because individuals who live in very rural places may not really understand the problems of big cities and the severity of these problems. Individuals living in very urban places will be more familiar with the problems faced in big cities and may have a better understanding of how much money is actually being spent to solve these problems and what other steps need to be taken in order to try to eradicate the problems of big cities.

Table 2-Model 4 shows the results for multivariate logistic regression for the independent variables considered characteristics of the person, personality characteristics, geographic identifiers, and the empathy total with the dependent variable Natcity. Race, region (South-Central), region (South-West), and the empathy total were found to be significant in model 4. Age, sex, education, income, party id (Democrat-Independent), party id (Democrat-Republican), party id (Democrat-other), region (South-Northeast), and the rural-urban continuum code were all found to be non-significant variables in Model 4. Age, education, party id (Democrat-Independent), party id (DemocratRepublican), party id (Democrat-other), and the rural-urban continuum codes were all positively associated with the dependent variable Natcity. Sex, race, income, region 
(South-Northeast), region (South-Central), region (South-West), and the empathy total were all negatively associated with the dependent variable Natcity.

In Table 2-Model 4, the odds are 57.7\% lower for minorities than for whites to feel that we are spending the right amount or too much on solving the problems of big cities. The odds-ratio indicates that the odds of an individual feeling that we are spending the right amount or too much on solving the problems of big cities are only .569 as large for individuals from the Central region, than for individuals from the South. The oddsratio indicates that the odds of an individual feeling that we are spending the right amount or too much on solving the problems of big cities are only .565 as large for individuals from the West, compared to individuals from the South. For each increase of one on the empathy scale going towards the highest level of empathy, the odds are $6.8 \%$ lower for an individual to feel that we are spending the right amount or too much on solving the problems of big cities. For each increase of 1 on the rural-urban continuum code scale (most urban-most rural), individuals are 1.062 times more likely to feel that we are spending the right amount or too much on solving the problems of big cities. When comparing an individual who is a 1 (most urban) with an individual who is a 9 (most rural), the individual who is from a very rural area will be 8.496 times more likely to feel that we are spending the right amount or too much on solving the problems of big cities, than the individual who is from a very urban area.

In Model 4, all of the independent variables are included. Race, region (SouthWest), and the empathy total are the only independent variables that are significant in all of the models they were used in. These three independent variables seem to have the most impact on the way a respondent feels about how much we are spending on solving 
the problems of big cities. It makes sense for minorities to be more likely to feel that too little is being spent on solving the problems of big cities than whites. There are large numbers of minorities that reside in big cities and as a result are faced with the problems of big cities each and everyday. People from the West are less likely than people from the South, to feel that we are spending the right amount or too much on solving the problems of big cities. This finding could be attributed to differences in the prevalence of different political parties in the two regions. Individuals that are the most empathic on the empathy scale will be more likely to feel that too little is being spent on solving the problems of big cities than individuals that are the least empathic on the empathy scale. This finding is accurate because individuals that are very empathic will be more likely to be able to put themselves in a position where they can actually feel for a person who experiences the problems of big cities. 
Table 3: Multivariate Logistic Regression for Peoptrbl

\begin{tabular}{|c|c|c|c|c|c|c|c|c|c|c|c|c|}
\hline & \multicolumn{3}{|c|}{ Model 1} & \multicolumn{3}{|c|}{ Model 2} & \multicolumn{3}{|c|}{ Model 3} & \multicolumn{3}{|c|}{ Model 4} \\
\hline & B & S.E & $\begin{array}{l}\text { Odds } \\
\text { Ratio }\end{array}$ & B & S.E. & $\begin{array}{l}\text { Odds } \\
\text { Ratio }\end{array}$ & $\mathbf{B}$ & S.E. & $\begin{array}{l}\text { Odds } \\
\text { Ratio }\end{array}$ & B & S.E. & $\begin{array}{l}\text { Odds } \\
\text { Ratio }\end{array}$ \\
\hline Age & .000 & .004 & 1.000 & .000 & .004 & 1.000 & .000 & .004 & 1.000 & -.004 & .004 & .996 \\
\hline Sex (Female) & $.412 *$ & .125 & 1.510 & $.374 *$ & .128 & 1.453 & $.373^{*}$ & .129 & 1.452 & -.028 & .143 & .972 \\
\hline Race (Minority) & -.122 & .156 & .885 & -.123 & .168 & .884 & -.154 & .171 & .857 & -.078 & .186 & .925 \\
\hline Education & & & & .000 & .054 & 1.000 & .014 & .055 & 1.014 & -.011 & .060 & .989 \\
\hline Income & & & & .014 & .088 & 1.014 & .025 & .089 & 1.025 & -.015 & .098 & .985 \\
\hline Party ID (Independent) & & & & -.217 & .154 & .805 & -.214 & .155 & .808 & -.272 & .166 & .762 \\
\hline Party ID (Republican) & & & & -.077 & .172 & .925 & -.157 & .175 & .855 & -.092 & .187 & .912 \\
\hline Party ID (other) & & & & .215 & .577 & 1.240 & .133 & .579 & 1.142 & .444 & .666 & 1.558 \\
\hline Region(Northeast) & & & & & & & $-.570 *$ & .177 & .565 & $-.465 *$ & .192 & .628 \\
\hline Region (Central) & & & & & & & $-.376 *$ & .172 & .686 & -.236 & .185 & .790 \\
\hline Region (West) & & & & & & & -.243 & .188 & .784 & -.114 & .201 & .892 \\
\hline Rural-Urban Continuum Code & & & & & & & .033 & .040 & 1.033 & .022 & .042 & 1.022 \\
\hline Empathy Total & & & & & & & & & & $.162 *$ & .015 & 1.176 \\
\hline Cox \& Snell R Square & Model & $1=.00$ & & Model & $2=.00$ & & Model & $=.019$ & & Model & $=.117$ & \\
\hline
\end{tabular}

*Significant at the .05 level

For each of the categorical variables, the reference categories/values are as follows:

Sex- Reference category male (1)

Race- Reference category white (0)

Party ID- Reference category Democrat (0)

Region- Reference category South (1) 
First, bivariate logistic regression was used to test each of the independent variables alone with the dependent variable Peoptrbl. The following independent variables were found to be significant when bivariate logistic regression was used: sex, region (South-Northeast), region (South-Central), and the empathy total. Age, race, education, income, political party (Democrat-Independent), political party (DemocratRepublican), political party (Democrat-other), region (South-West), and the rural-urban continuum code were all found to be non-significant variables. Now, I would like to look at how adding certain independent variables to each of the models will affect the significance level and overall impact on the model.

Table 3-Model 1 shows the results for multivariate logistic regression for the independent variables considered to be characteristics of the person with the dependent variable Peoptrbl. Sex is the only significant independent variable in Table 3-Model 1. Age and race were both found to be non-significant variables. Age and sex were both positively associated with the way that people feel about assisting people in trouble, while race was negatively associated with the way that people feel about assisting people in trouble. Females are 1.510 times more likely than males to agree with the statement, "Personally assisting people in trouble is very important to me.” This finding supports the hypothesis about sex which states that females are more compassionate than males. The odds are $11.5 \%$ lower for minorities than for whites to agree with the statement, "Personally assisting people in trouble is very important to me.” This finding does not support the hypothesis about race, because for this dependent variable whites are more likely than minorities to agree with the statement, "Personally assisting people in trouble is very important to me.” 
Table 3-Model 2 shows the results for multivariate logistic regression for the independent variables considered to be characteristics of the person and personality characteristics with the dependent variable Peoptrbl. Sex is the only significant independent variable in this model as well as in the previous model. Age, race, education, income, political party (Democrat-Independent), political party (DemocratRepublican), and political party (Democrat-other) were all found to be non-significant variables. Age, sex, education, income, and party id (Democrat-Other) were all positively associated with the way that people feel about assisting people in trouble. Race, party id (Democrat-Independent), and party id (Democrat-Republican) were all negatively associated with the way that people feel about personally assisting people in trouble.

In Table 3-Model 2, the odds are 45.3\% higher for females than for males to agree with the statement "Personally assisting people in trouble is very important to me." This finding also provides support for hypothesis about sex. Independents are only .805 as likely as Democrats, and Republicans are only .925 as likely as Democrats to agree with the statement, "Personally assisting people in trouble is very important to me." This finding supports the hypothesis that Democrats are more likely to be compassionate than any other political party, when it comes to Independents and Republicans. People classifying themselves as belonging to the political party “other" are 1.240 times more likely to agree with the statement, "Personally assisting people in trouble is very important to me" than Democrats are, and therefore this finding does not support the hypothesis on political party identification. 
Table 3-Model 3 shows the results for multivariate logistic regression for the independent variables considered to be characteristics of the person, personality characteristics, and geographic identifiers with the dependent variable Peoptrbl. Sex, region (South-Northeast), and region (South-Central) were all found to be significant in Table 3-Model 3. Age, race, education, income, political party (Democrat-Independent), political party (Democrat-Republican), political party (Democrat-other), region (SouthWest), and the rural-urban continuum code were all found to be non-significant variables. Age, sex, education, income, party id (Democrat-Other), and the rural-urban continuum codes were all found to be positively associated with the dependent variable Peoptrbl. Race, party id (Democrat-Independent), party id (Democrat-Republican), region (SouthNortheast), region (South-Central), and region (South-West) were all found to be negatively associated with the dependent variable Peoptrbl.

In Table 3-Model 3, females are 1.452 times more likely than males to agree with the statement, "Personally assisting people in trouble is very important to me.” This finding supports the hypothesis that females are more likely to have more compassionate attitudes and be more giving than males. The odds are $43.5 \%$ lower for people from the Northeast, than people from the South, to agree with the statement, "Personally assisting people in trouble is very important to me.” This finding supports the hypothesis that people from the South are more caring and giving than people from any other region of the country. The odds are 31.4\% lower for people from the Central region, than people from the South, to agree with the statement, "Personally assisting people in trouble is very important to me.” This finding also supports the hypothesis that people from the South are more compassionate and giving than people from any other region of the 
country. For each increase of 1 on the rural-urban continuum code scale (most urbanmost rural), the odds-ratio indicates that an individual is 1.033 times more likely to agree that personally assisting people in trouble is very important to them. When comparing an individual who is a 1 (most urban) with an individual who is a 9 (most rural), the individual who is a 9 will be 8.264 times more likely to agree with the statement, "Personally assisting people in trouble is very important to me" than the individual who is a 1 . This finding supports the hypothesis that rural people will be more compassionate and giving than urban people will be.

Table 3-Model 4 shows the results for multivariate logistic regression for the independent variables considered to be characteristics of the person, personality characteristics, geographic identifiers, and the empathy total with the dependent variable Peoptrbl. Region (South-Northeast) and the empathy total were the only two independent variables found to be significant in Table 3-Model 4. Age, sex, race, education, income, political party (Democrat-Independent), political party (Democrat-Republican), political party (Democrat-other), region (South-Central), region (South-West), and the rural-urban continuum code were all found to be non-significant variables. Age, sex, race, education, income, party id (Democrat-Independent), party id (Democrat-Republican), region (South-Northeast), region (South-Central), and region (South, West) were all found to be negatively associated with the dependent variable Peoptrbl. Party id (Democrat-Other), the rural-urban continuum codes, and the empathy total were all positively associated with the dependent variable Peoptrbl.

In Table 3-Model 4, the odds are $2.8 \%$ lower for females than for males to agree with the statement, "Personally assisting people in trouble is very important to me.” This 
finding does not support the hypothesis about sex for this study. It seems that when empathy is considered, sex is no longer important. Empathic males and females are both likely to be compassionate and giving to other people in need. The odds are $37.2 \%$ lower for people from the Northeast than people from the South to agree with the statement, "Personally assisting people in trouble is very important to me.” This finding supports the hypothesis that individuals from the South are more caring and giving than individuals from any other region of the country. For each 1 unit increase on the empathy scale going towards the highest level of empathy, an individual is 1.176 times more likely to agree with the statement, "Personally assisting people in trouble is very important to me.” When comparing an individual who has a score of 35 (high empathy) on the empathy scale with an individual who has a score of 7 (low empathy) on the empathy scale, the individual who has high empathy will be 32.928 times more likely to agree with the statement, "Personally assisting people in trouble is very important to me" than the individual who has low empathy. This finding supports our hypothesis that individuals who are more empathic will have more compassionate and giving attitudes than individuals who are less empathic. For each 1-unit increase on the rural-urban continuum code scale (most urban-most rural), the odds-ratio indicates that an individual is 1.022 times more likely to agree with the statement, "Personally assisting people in trouble is very important to me.” When comparing an individual who is a 1 (most urban) with an individual who is a 9 (most rural), the individual who is a 9 will be 8.176 times more likely to agree with the statement, "Personally assisting people in trouble is very important to me” than an individual who is a 1 . This finding supports our hypothesis that rural people are more compassionate and giving than urban people are. 


\section{$\underline{\text { Discussion and Conclusions }}$}

The purpose of this secondary data-analysis study was to discover the relationship between an individual's demographic characteristics and their feelings and actions towards the problem of homelessness, as well as any differences that exist between urban residents and rural resident's feelings and actions towards the problem of homelessness. Bivariate logistic regression and multivariate logistic regression were used to analyze the data. Several hypotheses were made before the study began. After analyzing the data, some hypotheses were supported while other hypotheses were not supported.

Each of the independent variables was operationalized by placing each variable into one of the following categories: characteristics of the person, personality characteristics, geographic identifiers, or the empathy total. The independent variables that fell under characteristics of the person were age, sex, and race. Personality characteristics consisted of education, income, and political party identification. The geographic identifiers were region of the country where the interview took place and the rural-urban continuum code of the respondent. The empathy total was comprised of seven items that asked about the person's level of empathy. For each of the three dependent variables, the different groups of independent variables were stepped in to the different models systematically. There were four models in each of the three tables, which consisted of the same independent variables for each model in each of the different tables.

First, I would like to discuss each of the three theories that this study was going to test and the results that were found. Each of the three theories that were tested are similar because they state that urban individuals will be less likely to help others than rural 
individuals. I will briefly re-state the basic premise of each theory. According to Subculture theory, individuals in rural areas will be more likely to help strangers in need than their urban counterparts will be. Social disorganization theory states that people in large cities, compared with people in small towns, experience deficits in the quality of interpersonal relations (Alexander, 1973). This theory, therefore, predicts that feelings and helping actions towards homeless individuals are going to be lower in large cities than in small towns. Environmental overload theory states that urbanites often fail to extend help to strangers because of environmental overload. This condition results from the high level of social stimulation in large cities. This theory predicts that individuals from large cities will be associated with less helping towards strangers than individuals from small towns.

Next, I would like to look at each of the three dependent variables to see if the theories were supported or were not supported. The first dependent variable was Givhmlss, which asked whether the respondent had given food or money to a homeless person in the past year. The results for Table 1 found that individuals from rural areas were less likely to have given food or money to a homeless person in the past year. These results did not provide support for Subculture theory, Social disorganization theory, or Environmental overload theory. This finding may be attributed to the fact that urban people encounter homeless individuals much more frequently than rural individuals encounter homeless individuals. As a result, an urban individual may have been more likely to have given food or money to a homeless person than a rural individual because they had many more opportunities to do so. 
The second dependent variable was Natcity, which asked whether the respondent felt we are spending too little or the right amount or too much on solving the problems of big cities. The results for Table 2 found that individuals from rural areas were more likely than individuals from urban areas to feel that we are spending the right amount or too much on solving the problems of big cities. This finding provides support for Subculture theory, Social Disorganization theory, and Environmental Overload theory. This finding is interesting. It seems plausible that rural people feel this way because they do not actually live in big cities, unlike their urban counterparts. Therefore, rural people may not have an accurate portrayal of the severity of the problems that exist in big cities and the money that is being spent on solving the problems of big cities.

The third dependent variable was Peoptrbl which asked whether the respondent agreed with the statement, "Personally assisting people in trouble is very important to me.” The results for Table 3 indicate that rural people were more likely than urban people to agree with the statement, "Personally assisting people in trouble is very important to me.” This finding provides support for Subculture theory, Social Disorganization theory, and Environmental Overload theory. I believe that most people would expect rural people to be more likely to agree with the statement, "Personally assisting people in trouble are very important to me” than urban people. This could be attributed to a variety of factors. Urban people may be more likely to pay no attention to people in trouble as compared to rural people. Rural people may be more likely to know the person who is in trouble, and as a result be more likely to assist that person.

Now, I would like to discuss some interesting findings for each of the dependent variables. The first dependent variable asked whether the respondent had given food or 
money to a homeless person in the past year and the results are displayed in Table 1. In Table 1-Model 3, region (South-West) is not significant because of the smaller sample size that makes up that area. If all respondents were included in that comparison, region (South-West) would probably have been significant. The smaller sample size makes the confidence interval narrower. For example, region (South-West) has a higher beta coefficient and odds ratio than sex does for Table 1-Model 3. Sex is significant because the sample consists of all 2,765 respondents in the sample. Region (South-West) only consists of a portion of the larger sample size of 2,765 respondents. When the empathy total is added to Table 1-Model 4, sex is no longer significant at the .05 level. This is an interesting finding, but not really surprising. It makes sense to say that highly empathic males and females will be equally as likely to have given food or money to a homeless person in the past year, regardless of sex. Empathy seems to be a rather predictive independent variable of whether or not an individual has given food or money to a homeless person in the past year. Table 1 has relatively low R squared values. The low values may be because there are a large number of variables that could influence whether an individual has given food or money to a homeless person in the past year, and this study included only a few of these variables.

The second dependent variable was Natcity, which asks the respondent whether we are spending too little or the right amount or too much on solving the problems of big cities. The results are displayed in Table 2. It is interesting to see that females and minorities are more likely than males and whites, to feel that we are spending too little on solving the problems of big cities. This finding is likely because females and minorities may be more likely to experience the problems of big cities than males and whites are. 
As a result of this, females and minorities may feel that if more money was spent on solving the problems of big cities, then they may be less likely to encounter such problems. It is interesting to see that age is not significant in Table 2-Model 1, because it has the highest odds-ratio of all the independent variables. If age were coded into categories, (Ex. 18-25 (0), 26-40 (1), 41-55 (3), 55+ (4) etc.) instead of being coded as how old (in years) the respondent was at the time of the interview, it would probably be a significant variable for the way a person feels about how much we are spending on solving the problems of big cities. It is also an interesting finding that income is not a significant independent variable in many of the models. This finding can be attributed to the large number of respondents who refused to answer the question asking about income.

The third dependent variable was Peoptrbl, which asks the respondent if they agree with the statement, "Personally assisting people in trouble is very important to me.” The results for Peoptrbl are displayed in Table 3. It is interesting to see that sex is positively associated and significant with Peoptrbl in the first 3 models of Table 3. In Table 3-Model 4, sex is no longer significant and is now negatively associated with agreeing with the statement "Personally assisting people in trouble is very important to me.” This finding shows that when empathy is included in the model, sex is not a significant predictor. There seems to be a strong difference between the way that people in the South and people in the Northeast feel about the statement, "Personally assisting people in trouble is very important to me.” Region (South-Northeast) is significant in both Model 3 and Model 4 of Table 3. This is interesting because there were not many significant independent variables associated with agreeing with the statement, 
"Personally assisting people in trouble is very important to me." It is very interesting that race is not significant in any model of Table 3. In each of the models in the other two tables, race was significant in each and every model.

In conclusion, this study found support for some hypotheses, while it did not provide support for other hypotheses. Subculture theory, Social Disorganization theory, and Environmental Overload theory were tested in this study. Both Natcity (the way a respondent felt about how much we are spending on solving the problems of big cities) and Peoptrbl (whether a respondent agrees that "Personally assisting a person in trouble is very important to me”) provided support for Subculture theory, Social Disorganization theory, and Environmental Overload theory. Givhmlss (whether a respondent has given food or money to a homeless person in the past year) did not provide support for Subculture theory, Social Disorganization theory, and Environmental Overload theory. Race was found to be the most significant and predictive independent variable. Race was significant in every model for the first two tables. This finding surprised me because previous studies have stated that race did not play an important role in the way that people felt and acted towards the problem of homelessness. Also, the empathy total seemed to play a crucial role in changing the significance levels in Model 4 of each table. Since empathy was only added to each table in Model 4, it is interesting to see how values changed when empathy was included. The empathy total seems to be a dominating variable with the way a person feels and acts towards the problem of homelessness. There are a variety of demographic variables that are no longer significant in any of the three tables-Model 4, when the empathy total is included in the model. 
It seems to be that people with money and power could do something to remedy the problem of homelessness, but do not seem to care enough to focus on working towards eradicating homelessness. People from lower classes, with lower levels of education and very limited power, seem to care about helping to solve the problem of homelessness, but do not have the means to do so. This issue needs to be addressed and studied in depth.

\section{Limitations and Further Study}

\section{Limitations}

Since the General Social Survey uses in-person interviews to collect the data, participants may tend to give "socially desirable" responses rather than a response that expresses their actual feelings and/or behavior. This may lead to inaccurate responses on a variety of topics and thus lead to biased data. It may be very likely that people wanted to act more compassionate and giving than they actually are.

The response rate is $70 \%$ for the 2002 General Social Survey. That is a fairly high response rate, but there is still a $30 \%$ non-response rate. It may be interesting to look at what types of people seem to respond to try and see if there are any patterns and/or trends existing among the individuals that respond.

This study excludes institutionalized adults. If institutionalized adults were included in the sample, the data may appear quite differently than the way it appears now with them being excluded from the sample.

Since I am selecting variables that I think may be influential on one's view of the problem of homelessness, it may not be the most representative option since my own 
biases are included. My selection of variables represents only one approach among many for examining the issue.

The National Opinion Research Center (NORC) asked some questions in only a random sub-sample of the households, asking other questions in the other households. All of the dependent variables used in this study were asked of only a random sub-sample of households. This limits my study by reducing the sample size. Some questions were asked of all 2,765 respondents while the questions for my dependent variables asked between 1,239-1,380 respondents. This should not have a significant impact on my research because the sample sizes are still large.

\section{Significance of the Study}

A study of how urban residents and rural residents feel and act towards homelessness is important for several reasons. First, this study may influence policymakers to improve policies on homelessness by taking into consideration the public's opinions and actions towards homelessness. Hopefully, as a result of this study, more policies will be made regarding homeless and/or poor people. Homelessness has been a problem in this country for many years. It seems that if there were more policies out there to help the homeless, there would be less homeless individuals in the United States. Eventually, with enough hard work, dedication, and assistance there could be very few homeless individuals in this country. Next, this study will add to the scholarly literature on individual's feelings towards the homeless/poor population and this is important because it is a difficult topic to study and thus there is not a great deal of research done on the topic. This study will also contribute to the scholarly literature on the topic because the majority of studies actually look at the homeless population while this study 
is intended to look at how the general population feels and acts towards homelessness. This study will also add to the scholarly literature because it is unique in the way that it compares the general population's view of homelessness on a rural-urban continuum. Finally, this study will provide useful information to social scientists, politicians, and other policy makers. The results may influence social scientists to do further research on the problem of homelessness.

Future directions include addressing the role of employment and social ties in producing homelessness, comparing economic and social situations of homeless and nonhomeless persons, evaluating programs to aid homeless persons, and developing international comparisons of homelessness. Politicians may be influenced by the opinions of individuals in the study when making their campaigns etc. The data that was analyzed for this study is very informative and serves an important purpose. It would be an interesting study to collect your own data about this topic, but for all practical purposes it was not feasible to do at this time. 


\section{REFERENCES}

Adorno, T., Frenkel-Brunswick E., Levinson, D., and R. Sanford. 1950. "The Authoritarian Personality”, New York: Harper.

Alexander, C. 1973. "The city as a Mechanism for Sustaining Human Contact.” Pp. 239-74 in Urban Man: The Psychology of Urban Survival, edited by John Helmer And Neil A. Eddington. New York: Free Press.

Amato, Paul R. 1993. "Urban-Rural Differences in Helping Friends and Family Members,” Social Psychology Quarterly, Vol. 56, No 4, 1993, pg. 249-262.

Buck, P.O., Toro, P.A., and Ramos, M. 2004. "Media and Professional Interest in Homelessness Over Three Decades.” (1974-2003). Analyses of Social Issues and Public Policy.

Bunis, W.K., Yancik, A., and Snow, D.A. 1996. "The Cultural Patterning of Sympathy Toward the Homeless and other Victims of Misfortune”, Social Problems, 43(4): 387-402.

Committee of the Regions. 1999. Housing and the homeless. (Opinion of the European Union Committee of the Regions: CdR 376/98 fin E/o). Brussels: European Union.

Curley, Alexandra M. 2005. "Theories of Urban Poverty and Implications for Public Housing Policy”, Journal of Sociology and Social Welfare, Vol. 32, No. 2, June, 2005.

Daly, G. 1996. “Homeless: Policies, Strategies and Lives on the Street.” (London, Routledge).

Farrington, A. and W.P. Robinson. 1999. "Homelessness and Strategies of Identity Maintenance: A Participant Observation Study”, Journal of Community and Applied Social Psychology 9,: 175-194.

Federico, Christopher M. 2004. "When Do Welfare Attitudes Become Racialized? The Paradoxical Effects of Education.” American Journal of Political Science, Vol. 48, No. 2, April 2004, pg. 374-391.

First, Richard, Rife, John, and Toomey, Beverly. 1994. "Homelessness in Rural Areas: Causes, Patterns, and Trends.” Social Work, Vol. 39, January 1994, Issue 1, 97-108.

Fitchen, Janet M. 1992. "On the Edge of Homelessness: Rural Poverty and Housing Insecurity,” Rural Sociology, Vol. 57, No. 2, pgs. 173-195.

Flanagan C, Jonsson B, Botcheva B, Csapo B, Bowes J, Macek P, Averina I, Sheblanova E. 1999. "Adolescents and the Social Contract: Developmental Roots of Citizenship In Seven Countries. In Roots of Civic Identity: International Perspectives on 
Community Service and Activism in Youth, pp. 135-155. Cambridge: Cambridge Univ. Press.

Flynt, W. 1996. "Rural Poverty in America,” National Forum, 76(3), 32-35.

Forte, James. 2002. "Not in my Social World: A Cultural Analysis of Media Representations, Contested Spaces, and Sympathy for the Homeless", Journal of Sociology and Social Welfare 29, pg. 4.

Furnham, Adrian. 1996. "Attributions for the Increase in Urban Homelessness”, Journal Of Social Behavior and Personality, Vol. 11, Issue 1, pg. 189.

Hewitt, Christopher. 1996. "Estimating the Number of Homeless: Media Misrepresentation of an Urban Problem”, Journal of Urban Affairs, Vol. 18 Issue 4, 431.

Hill, Ronald. 2003. "Homelessness in the US: An Ethnographic Look at Consumption Strategies", Journal of Community and Applied Social Psychology 13: 128-138.

HUD website:

http://www.hud.gov

Kearns, Kevin. 1984. "Homelessness in Dublin: An Irish Urban Disorder:, American Journal of Economics and Sociology, vol. 43, No. 2 (April, 1984).

Kelling, K. 1991. “Older Homeless People in London (Age Concerns, London, UK).

Layton, J. 2000. "Homelessness: The Masking and Unmasking of a Crises”, Penguin Books, Toronto, Canada.

Maio, G.R., Bell, D.W., and Esses, V.M. 1996. "Ambivalence and Persuasion: The Processing of Messages about Immigrant Groups”, Journal of Experimental Social Psychology, 32, 513-536.

Mathieu, Arline. 1993. "The Medicalization of Homelessness and the Theater of Repression”, Medical Anthropology Quarterly, vol. 7, No. 2 (June, 1993), pp. 170$-184$.

Miller, L., and Seligman, M.E.P. 1999. "Beliefs about Responsibility and Improvement Associated with Liberal-Conservative Justice Beliefs”, Psychological Reports, 84, 329-338.

Mills, C. Wright. 1959. “The Sociological Imagination”, Oxford University Press, U.S.A.

Morgan, M.M., Goddard, H.W., and Givens, S.N. 1997. "Factors that Influence Willingness to Help the Homeless", Journal of Social Distress and the Homeless, 
6(1), 1997.

National Coalition for the Homeless website:

http://www.nationalhomeless.org

Nix, Crystal. 1986. "Taking Account of the Hidden Homeless", The New York Times. June 22, 1986.

Osborne, R.E. 2002. "I may be homeless, but I'm not helpless": Costs and Benefits of Identifying with Homelessness. Self and Identity, 1, 43-52.

Phelan, Link, Stueve, and Moore. 1995. "Education, Social Liberalism, and Economic Conservatism: Attitudes Toward Homeless People.” American Sociological Review, Vol. 60, (February: 126-140).

Phelan, J., Link, B., Moore, R., and Stueve, A. 1997 "The Stigma of Homelessness: The Impact of the Label "Homeless" on Attitudes Toward Poor Persons." Social Psychology Quarterly, Vol. 60, No. 4 (Dec., 1997), pp. 323-337.

Pleace, Nicholas. 2000. "The New Consensus, the Old Consensus and the Provision of Services for People Sleeping Rough.” Housing Studies, Vol. 15, No. 4 (2000), pp. 581-594.

Rokach, Ami. 2003. "The Lonely and Homeless: Causes and Consequences”, Social Indicators Research 69: 37-50, 2004.

Rosenberg, Morris. 1990. "Reflexivity and Emotions”, Social Psychology Quarterly 53:3-12.

Shinn, Marybeth, and Colleen Gillespie. 1994. "The Roles of Housing and Poverty in the Origins of Homelessness.” American Behavioral Scientist 37: 505-21.

Shlay, Anne B., and Peter H. Rossi 1992. "Social Science Research and Contemporary Studies of Homelessness.” Annual Review of Sociology 18: 129-60.

Snow, D.A., and Anderson, L. 1987. "Identity Work Among the Homeless: The Verbal Construction and Avowal of Personal Identities." American Journal of Sociology, 92, 1336-1371.

Substance Abuse and Mental Health Services Administration website: http://www.samhsa.gov

Tompsett, Carolyn et al. 2003. "Homelessness in the US and Germany: A Cross National Analysis", Journal of Community and Applied Social Psychology., 13: 240-257. 
Toohey, Shinn, and Weitzman. 2004. "Social Networks and Homelessness Among Women Heads of Household”, American Journal of Community Psychology, Vol. 33.

Toro, P.A. and McDonnell, D.M. 1992. "Beliefs, Attitudes, and Knowledge about Homelessness: A Survey of the General Public.” American Journal of Community Psychology, 20(1), 53-80.

Urban Institute website:

http://www.urban.org

U.S. Department of Housing and Urban Development. 1999. "1999 Continuum of Care And HOPWA Application.” Washington D.C.: U.S. Government Printing Office.

Wilson, John. 2000. “Volunteering”, Annual Reviews of Sociology, 26: 215-40.

Zlotnick, C., Robertson, M.J., and Lahiff, M. 1999. "Getting Off the Streets: Economic Resources and Residential Exits Among Homeless Adults.” Journal of Community Psychology, 27, 209-224.

Zlotnick, Robertson, and Tam 2002. "Substance Use and Labor Force Participation Among Homeless Adults”, Drug Alcohol Abuse, 28(1), 37-53, 2002. 